\title{
Forced-air-warming for hypothermia prevention in entrapment after road traffic collisions
}

\author{
Karl-Christian Thies ${ }^{1 *}$, Simon Cusack ${ }^{2}$, Robbie Kerry ${ }^{3}$ and Andrew Thurgood ${ }^{4}$ \\ ${ }^{1}$ Consultant in Anaesthesia and Pre-hospital Emergency Medicine, Mercia Accident Rescue Service, UK \\ ${ }^{2}$ Watch Commander, Paramedic - Prehospital \& Urgent Care, Hereford And Worcester Fire \& Rescue Service, UK \\ ${ }^{3}$ Consultant Anaesthetist, CARE Team, Mercia Accident Rescue Service, UK \\ ${ }^{4}$ Consultant Nurse in Pre-hospital Care, Mercia Accident Rescue Service, UK
}

\begin{abstract}
Objective: Entrapment is a common feature of motor vehicle accidents. Seriously injured patients suffer from rapid loss of body temperature, which aggravates the severity of their injuries. Hypothermia is a predictor of mortality in major trauma and therefore more efforts should be undertaken to limit heat loss in the pre-hospital field. Due to the complex nature of some entrapments and prolonged time required for technical rescue strategies to be employed, some patient will inevitably become severely hypothermic. This is compounded in austere environments when ambient temperature is low. Several methods have been tried to prevent pre-hospital hypothermia, but none have produced favorable results.

Forced-Air-Warming (FAW) is the method of choice to prevent hypothermia in the operating room environment. To assess the feasibility of forced air warming in entrapment we have carried out the following experiment.

Methods: we have carried out a simulated extrication in cold weather conditions using an outdoor heater as FAW device to prevent accidental hypothermia in a volunteer.

Results: Multiple site temperature recordings indicate no heat loss when the FAW is used, but a significant heat loss without the use of FAW. Feedback from the attending services confirmed that the method is feasible.
\end{abstract}

Conclusion: Our results indicate that forced air warming could be used to treat hypothermia in entrapped victims after road traffic accidents and that a prospective feasibility study is justified.

\section{Introduction}

Entrapment is a common feature of road traffic collisions (RTC). Seriously injured patients suffer from rapid loss of body temperature aggravating the severity of their injuries $[1,2]$. New approaches such as "scoop to skin" and invasive airway management (RSI) frequently conducted outside of an ambulance to allow 360-degree access to have led to increased patient exposure and heat loss [3,4]. Hypothermia is a predictor of mortality in major trauma and efforts should focus on limiting heat loss in the pre-hospital field particularly in patients that are exposed to the environments during sometimes complex and time consuming extrication procedures in cold and wet weather conditions $[5,6]$.

Many techniques of passive and active re-warming in the field have been tried but none have proven to be very effective [7]. Forced Air Warming (FAW) however, was introduced into hospital practice 25 years ago and is now the method of choice to limit intra-operative heat loss. Based on a laboratory study, we have simulated an RTC entrapment to investigate whether the concept of Forced-Air-Warming can be transferred to the outdoor environment and whether a clinical field study on hypothermia prevention with FAW in entrapment is justified [7].

\section{Method}

We conducted a simulated post-RTC extrication outdoors in cold weather conditions. A Polarn 4000 System (diesel-electric heater,
Eberspächer, Esslingen, Germany) was used for Forced-Air-Warming as described below.

In line with UK regulation this experiment did not require ethical approval, which was confirmed by the corresponding ethics committee. All participants gave consent to take part.

The experiment consisted of 2 components,

1. Feasibility assessment of FAW under extrication

2. Efficacy assessment through continuous multiple site body temperature monitoring with and without FAW.

For the feasibility assessment Hereford and Worcester Fire and Rescue Service (HWFRS) carried out a simulated extrication of a volunteer from a Peugeot 206 on a November the ambient temperature remained at $6^{\circ} \mathrm{C}$ throughout the experiment. The lightly dressed

Correspondence to: Karl-Christian Thies, Consultant in Anaesthesia and Prehospital Emergency Medicine, Mercia Accident Rescue Service, PO Box 350 Malvern WR14 9HE, UK, Tel: +44 845260 7061; E-mail: KCThies@gmail.com

Key words: hypothermia, trauma, entrapment, forced-air-warming, road trafficcollision

Received: November 20, 2017; Accepted: November 24, 2017; Published: November 27, 2017 
volunteer (first author) took seat in the driving seat of the Peugeot. Both doors were kept open to simulate a realistic temperature drop in the car after an accident. After 10 minutes (HWFRS Attendance Target) the volunteer was covered with a plastic sheet, which is used standard by HWFRS to protect entrapped victims from of debris. The outlet hose of the heater was placed underneath the plastic sheet into the foot well of the car. The medic applied a facemask to the volunteer to simulate oxygen administration; a hard-cervical collar was applied to immobilize the neck; insertion of a venous access was simulated and a ECG monitor was attached to the volunteer. The extrication commenced, and a full roof removal was carried out, the volunteer was placed onto an extrication board and then removed from the car.

After conclusion of the extrication all participants were interviewed regarding their perception of the feasibility of the setup.

For the efficacy assessment the volunteer took up the same position in the disassembled car as previously. He wore multiple temperature probes and further probes were placed at steering wheel level (car/under cover temperature) and outside the vehicle (ambient temperature) for continuous temperature recording. The volunteer again cooled down for ten minutes in ambient temperature before the recordings commenced. At this point the plastic sheet was put over the volunteer and the heater was installed as described above. Skin temperatures were recorded for 20 minutes with the heater on (Phase A).

After 20 minutes the heater was turned off and the sheet was removed. Then the volunteer remained seated in the disassembled car and was exposed to ambient temperature for a further ten minutes (Phase B) before the sheet was put over him. No active heating was used this time. Skin temperatures were recorded for another 20 minutes (Phase C) before we concluded the experiment.

\section{Results}

\section{Feasibility Assessment}

Fire Service: the firemen felt the extrication was not significantly impeded by the heating system. Also, the plastic sheet is part of the standard HWFRS extrication procedure and did not hamper their work.

Consideration to positioning of the heater and the exhaust would require attention as fuel spillage after an RTC is a common finding and the introduction of hot exhaust on spilt fuel could be problematic. This could be overcome with a long hose, which would allow the heater to remain out of the inner cordon.

High visibility outer layer on the hose would reduce the possibility of tripping over the hose.

Having a securing clip on the end of the hose would allow the direction of hot air to be more controlled in the direction the rescuers desire and reduce the possibility of the hose moving too close to the patient and causing discomfort, which they may not be able to make rescuers aware of if there is neurological deficit.

Medic: the medic found that the opacity of the sheet slightly impeded patient assessment; a clear sheet would be preferable. He also felt patient access was slightly limited. He suggested the plastic sheet could be slit to expose the patient's head and allow for access from the side.

Volunteer: the volunteer felt comfortable during the extrication with the heating system on. At one point he complained about his right ankle getting warm, which was caused by the hot air stream directly pointing towards his leg. This was corrected by repositioning the outlet of the heater.
Observer: the encapsulation of the patient in a plastic sheet for protection during extrication is standard practice to the fire and rescue service. This experiment indicates that the impact on the technical rescue elements is minimal.

\section{Efficacy assessment}

Please see temperature recordings in Figure 2.

During the first 20 minutes (Phase A) the temperature underneath the sheet rose continuously. The skin temperature was rising linearly during this period.

After removal of the sheet all temperatures dropped (Phase B), apart from the volunteers groin temperature, which was initially rising; this was caused by the volunteer having accidently placed his right hand over the groin-probe. The volunteer was asked to reposition his hand, which led to an immediate fall in groin temperature.

After eleven minutes the sheet was refitted, but the heater was not used. (Phase C). The temperature under the cover rose to $17^{\circ} \mathrm{C}$ and then declined steadily. Chest and forehead temperature increased slowly, whereas groin and calf temperature decreased.

\section{Discussion}

Seriously injured patients lose the ability to generate sufficient heat to maintain body temperature. Environmental factors can aggravate the inevitable heat loss and especially entrapped patients in austere environments undergoing prolonged extrication can suffer severe hypothermia [8]. Even though there is some evidence regarding hypothermia mitigation during hospital transport, there is no literature on hypothermia prevention in patients that are still entrapped [9]. In general, entrapped patients are not easily accessible which renders conventional methods as heating blankets or heat packs less applicable [10]

Our experiment compares the heat retention under FAW against no protection against the plastic sheet used standard by HWFRS to protect entrapped patients against debris. The results are clearly in favor of Forced-Air-Warming. We acknowledge that we cannot generalize our results as they are based on a single experiment. However, prevention of heat loss during entrapment with FAW seems to be possible and feasible. Only slight modifications of our model are required to improve access and to prevent burn injuries. A heating system that provides the

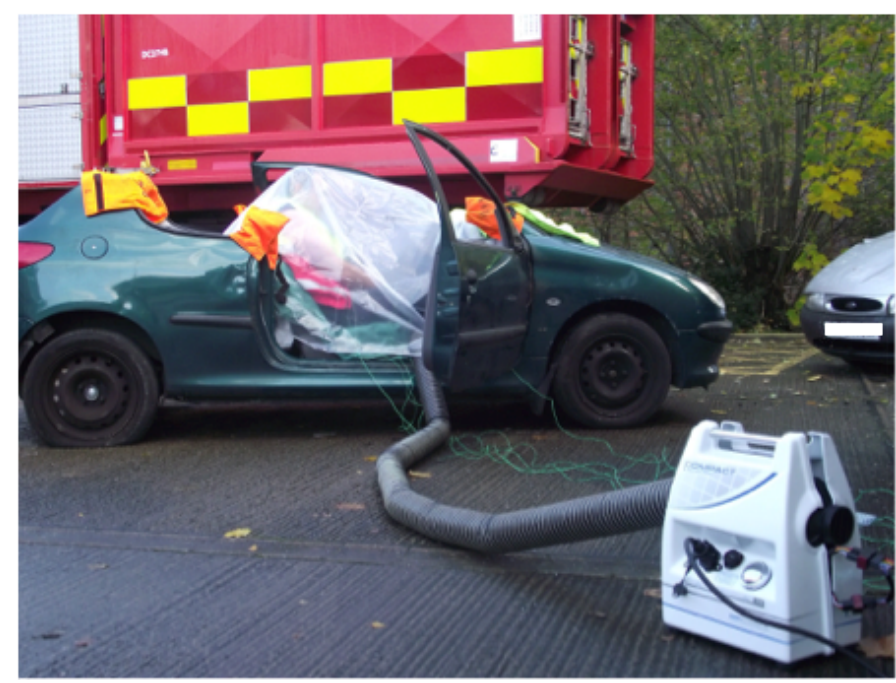

Figure 1. (Forced Air Warming in Action): Volunteer underneath a plastic cover, which is used by HWFRS to protect entrapped victims from debris during extrication; heated air is blown underneath the cover using a Polarn 4000 (Eberspächer, Germany) outdoor heater. 


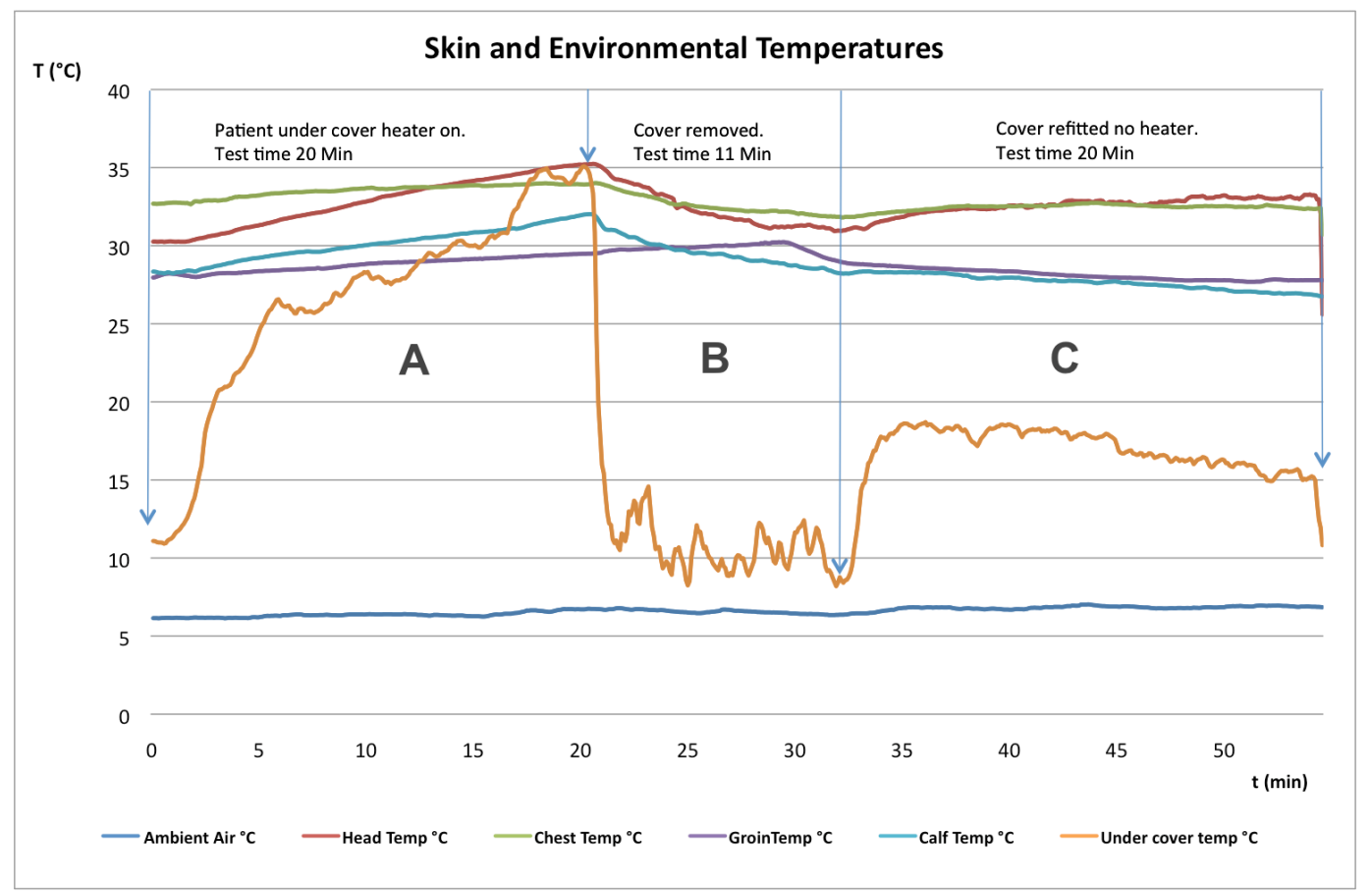

Figure 2. (Skin and Environmental Temperatures): Multiple site temperature recordings during the different phases of the Efficacy Assessment. During Phase A the volunteer is covered with a plastic sheet and the heater is on. During Phase B the heater is turned off and the sheet is removed. During Phase C the plastic sheet is refitted but the heater remains switched off.

same heat output but delivers higher airflows would be desirable. This would decrease the air temperature at the outlet and also allow for better compensation of unavoidable leaks.

\section{Conclusion}

Our experiment indicates that Forced-Air-Warming could be a promising technology to reduce heat loss in entrapped major trauma patients in austere environments; a prospective clinical study is justified to confirm our preliminary results.

\section{Authorship and contributions}

All authors contributed to the experiment and writing and reviewing the manuscript.

\section{Acknowledgements}

We would like to thank Eberspächer UK for providing the Polarn 4000 heater and their support with the temperature recordings.

\section{Funding}

None

\section{Competing interests}

None of the authors have any conflict of interests.

The experiment was supported by Eberspächer UK, who have supplied the heating system and conducted the temperature measurements.

\section{Ethical approval and consent to participate}

All participants gave consent to participate in the experiment.

The regional ethical (Birmingham Children's Hospital, UK) committee waived the need for approval.

The volunteer undergoing extrication was the first author.

\section{References}

1. Helm M, Lampl L, Hauke J, Bock KH (1995) Accidental hypothermia in trauma patients. Is it relevant to preclinical emergency treatment? Anaesthesist 44: 101-107. [Crossref]

2. Weuster M, Brück A, Lippross S, Menzdorf L, Fitschen-Oestern S, et al. (2016) Epidemiology of accidental hypothermia in polytrauma patients: An analysis of 15,230 patients of the TraumaRegister DGU. J Trauma Acute Care Surg 81: 905-912. [Crossref]

3. Moss R, Porter K, Greaves I (2013) Minimal patient handling: a faculty of prehospital care consensus statement. Emerg Med J 30: 1065-1066. [Crossref]

4. Association of Anaesthetists of Great Britain \& Ireland Safety Guideline. Pre- hospita Anaesthesia. 2009. https://www.aagbi.org/sites/default/files/prehospital_glossy09.pdf

5. Balvers K, Van der Horst M, Graumans M, Boer C, Binnekade JM, et al. (2016) Hypothermia as a predictor for mortality in trauma patients at admittance to the Intensive Care Unit. J Emerg Trauma Shock 9: 97-102. [Crossref]

6. Duchesne JC, McSwain NE Jr, Cotton BA, Hunt JP, Dellavolpe J, et al. (2010) Damage control resuscitation: the new face of damage control. J Trauma 69: 976-990. [Crossref]

7. Jebens C (2013) Vergleich präklinischer Behandlungsoptionen der akzidentellen Hypothermie nach Einklemmungstrauma Inaugural-Dissertation zur Erlangung des Doktorgrades der Medzinischen Fakultät der Universität Göttingen. Last accessed November 15th 2017. [Crossref]

8. Lapostolle F, Couvreur J, Koch FX, Savary D, et al. (2017) Hypothermia in trauma victims at first arrival of ambulance personnel: an observational study with assessment of risk factors. Scand J Trauma Resusc Emerg Med 25: 43. [Crossref]

9. Lundgren P, Henriksson O, Naredi P, Björnstig U (2011) The effect of active warming in prehospital trauma care during road and air ambulance transportation - a clinical randomized trial. Scand J Trauma Resusc Emerg Med 19: 59. [Crossref]

10. Thomassen O, Færevik H, Osterås O, Sunde GA, Zakariassen E, et al. (2011) Comparison of three different prehospital wrapping methods for preventing hypothermia-a crossover study in humans. Scand J Trauma Resusc Emerg Med 19: 41. [Crossref]

Copyright: (C)2017 Thies KC. This is an open-access article distributed under the terms of the Creative Commons Attribution License, which permits unrestricted use, distribution, and reproduction in any medium, provided the original author and source are credited. 